\title{
Análisis prospectivo-educativo del impacto del huracán Max en una comunidad de Guerrero
}

\author{
Prospective and Educative Analysis of the Impact of Hurricane Max in a \\ Guerrero Community
}

Análise prospectivo-educacional do impacto do furacão Max em uma comunidade de Guerrero

Ramón Bedolla Solano

Universidad Autónoma de Guerrero, México rabedsol@hotmail.com https://orcid.org/0000-0001-6219-4953

Adriana Miranda Esteban Universidad Autónoma de Guerrero, México mar86_05@hotmail.com https://orcid.org/0000-0003-4313-6146

Juan José Bedolla Solano*

Tecnológico Nacional de México, Instituto Tecnológico de Acapulco, México jjosebedolla@hotmail.com https://orcid.org/0000-0001-6999-8823

Oscar Sánchez Adame* Universidad Autónoma de Guerrero, México msposcar@gmail.com http://orcid.org/0000-0001-5202-3835

Autores de correspondencia* 


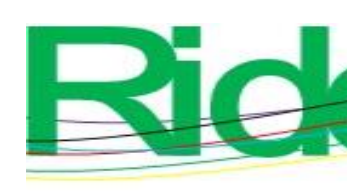

Revista Iberoamericana para la Investigación y el Desarrollo Educativo ISSN $2007-7467$

\section{Resumen}

El huracán Max ocurrió en septiembre de 2017. En una comunidad de Costa Chica, Guerrero, causó efectos negativos en lo ambiental, económico y social. El objetivo de este trabajo fue analizar el impacto social de dichas afectaciones para identificar medidas de prevención o mitigación ante eventos futuros considerando la adaptación de la cultura del riesgo y la Educación Ambiental para la Sustentabilidad (EAS). Se aplicó una entrevista no estructurada a ciudadanos afectados que contempló variables relacionadas con el ambiente, la economía, la sociedad, la percepción del riesgo y la EAS. Los resultados de este análisis evidenciaron daños en el ambiente: caída de árboles, desbordamiento e inundaciones; en cuanto a lo económico, la población perdió bienes materiales, animales y afectaciones en sus casas; en cuanto a lo social, las personas sufrieron daños físicos y emocionales; hubo afectaciones en los servicios de agua y de electricidad, y, por ende, falta de alimentos. También quedó al descubierto la desvinculación que existe entre sociedad y autoridad gubernamental en situaciones de emergencia. Experiencias como estas vuelven necesario fomentar en la población la cultura de riesgo ante eventos naturales y promover la EAS con miras a desarrollar habilidades y actitudes de cuidado y preservación del medio ambiente.

Palabras clave: cultura de riesgo, educación ambiental para la sustentabilidad, huracanes, medio ambiente.

\section{Abstract}

Hurricane Max occurred in September 2017. In Costa Chica, Guerrero, it caused negative environmental, economic and social effects. The objective of this work was to analyze the social impact of said affectations to identify prevention or mitigation measures in the face of future events, considering the adaptation of the risk culture and Environmental Education for Sustainability (EES). An unstructured interview was applied to affected citizens that considered variables related to the environment, the economy, society, the perception of risk and the EES. The results of this analysis showed damage to the environment: falling trees, overflowing and flooding; economically, the population lost material goods, animals and some damages in their houses; as for the social, people suffered physical and emotional damage; there were impacts on water and electricity services, and, therefore, lack of food. The disconnection that exists between society and government authority in emergency situations was also exposed. It is necessary to foster a culture of risk in the face of natural 


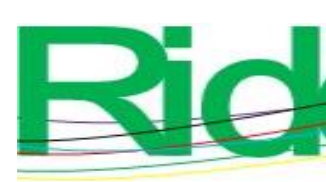

Revista Iberoamericana para la Investigación y el Desarrollo Educativo ISSN $2007-7467$

events in the population and promote EES with a view to developing skills and attitudes of care and preservation of the environment.

Keywords: risk culture, environmental education for sustainability, hurricanes, environment.

\section{Resumo}

O furacão Max ocorreu em setembro de 2017. Na comunidade de Costa Chica, Guerrero, causou efeitos ambientais, econômicos e sociais negativos. O objetivo deste trabalho foi analisar o impacto social destes efeitos para identificar medidas de prevenção ou mitigação face a eventos futuros, considerando a adaptação da cultura de risco e educação ambiental para a sustentabilidade (EAS). Uma entrevista não estruturada foi aplicada aos cidadãos afetados que considerou variáveis relacionadas ao meio ambiente, à economia, à sociedade, à percepção de risco e ao EAS. Os resultados desta análise apontaram danos ao meio ambiente: queda de árvores, transbordamento e inundação; economicamente, a população perdeu bens materiais, animais; e afetações á casa; quanto ao social, as pessoas sofreram danos físicos e emocionais; houve impactos nos serviços de água e eletricidade e, portanto, falta de alimentos. Também foi exposta a desconexão que existe entre a sociedade e o poder público em situações de emergência. É necessário fomentar uma cultura de risco face aos acontecimentos naturais na população e promover a EAS com vista ao desenvolvimento de competências e atitudes de cuidado e preservação do meio ambiente.

Palavras-chave: cultura de risco, educação ambiental para a sustentabilidade, furacões, meio ambiente.

Fecha Recepción: Agosto 2020

Fecha Aceptación: Febrero 2021 


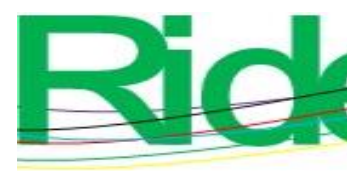

Revista Iberoamericana para la Investigación y el Desarrollo Educativo ISSN $2007-7467$

en sus parcelas o huertos, así como pérdida de animales, vacas, caballos, aves de corral, que les arrebató la corriente.

En el aspecto social, algunas personas sufrieron problemas de salud física y emocional, por ejemplo, enfermedades de la piel y resfriados; también hubo personas que mostraron sentimientos de tristeza por la pérdida de sus bienes, temor y nerviosismo por lo que sucedió al paso del huracán. En cuanto a los servicios de luz, telefonía, agua y transporte, estos fueron interrumpidos debido a que caminos y postes se vinieron abajo por los fuertes aires y corrientes de agua, por ende, las tortillerías y tiendas de la comunidad sufrieron de desabasto. Algunos comentaron que se observó el apoyo solidario de algunos integrantes de la comunidad para sacar de sus viviendas a personas cuyas casas se habían inundado. La ayuda de las autoridades del municipio y del Gobierno estatal llegó luego del paso del evento. Después de algunos días se observó la llegada de despensas, de ropa, colchones, colchonetas por parte de algunas instituciones gubernamentales y no gubernamentales, así como de algunos particulares, que apoyaron con bienes y con dinero en efectivo, principalmente de paisanos que radicaban en Estados Unidos o grupos de la sociedad civil, de Ciudad de México, sobre todo, que se organizaron para apoyar a su gente. También se destacó el apoyo de la parroquia de la Sagrada Familia de la comunidad y de algunas instituciones educativas de otros municipios, principalmente de Acapulco. Algunas escuelas de nivel superior de la Universidad Autónoma de Guerrero apoyaron con despensas, ropa y prestando servicios de salud gratuitos.

Otros aspectos que abonaron la comprensión de las causas y afectaciones del desastre y afectación ocurrida fue la falta de una cultura ambiental en la población, es decir, muchas personas no son conscientes del cuidado de los recursos naturales y de la preservación del medio ambiente. Se identificaron algunas problemáticas como el acarreo de arena del arroyo de Las Vigas, falta de desazolve de residuos que taponan las salidas de agua, acumulación de residuos o basura en lugares inadecuados y cerca o dentro de canales y arroyos, modificación al relieve de terrenos y una insuficiente percepción del riesgo por parte de algunas personas ante huracanes o ciclones.

Muchos fenómenos naturales suelen suceder en momentos inesperados. Estos se asocian con la alteración que el ser humano hace al medio ambiente a través de las actividades antropogénicas y que, de algún modo, llegan afectar al clima del planeta. Cuando se alude a un fenómeno natural no se hace referencia exclusivamente a huracanes, sino también a tsunamis, granizadas, nevadas, todos los cuales pueden causar desastres y afectaciones en la 


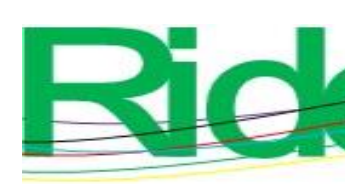

Revista Iberoamericana para la Investigación y el Desarrollo Educativo ISSN $2007-7467$

población; no obstante, lo que le tocó vivir a la población de Las Vigas fue un huracán y, por ende, esta experiencia marca la pauta para pensar prospectivamente maneras de enfrentar afectaciones a raíz de este tipo en particular. Sin duda una herramienta muy importante es fomentar la cultura de riesgo y promover la educación ambiental para la sustentabilidad. A través de esta educación, se puede lograr promover conocimientos, habilidades y actitudes sobre el cuidado y preservación del medio, que es fundamental para la subsistencia humana.

La educación ambiental tiene el propósito de que las personas adquieran conciencia de su entorno y puedan realizar cambios en sus valores, conductas y estilos de vida, así como ampliar sus conocimientos para impulsar los procesos de prevención y resolución de los problemas ambientales presentes y futuros (Olaguez y Espino, 2013). Al investigar las relaciones entre la sociedad y la naturaleza desde una perspectiva de la educación ambiental, surge la necesidad de plantear formas alternativas que permitan construir un desarrollo sustentable. La prospectiva intenta mostrar las relaciones entre los futuros posibles y ciertas decisiones del presente, a fin de movilizar los esfuerzos sociales hacia el cambio constructivo (Tréllez, 2004).

La educación ambiental debe negarse a ser reducida a un conjunto de prácticas de naturaleza, a centrarse exclusivamente en la contaminación y en los futuros trágicos que nos esperan, a convertirse en la última voz que clama antes del desastre. La prospectiva ambiental, en particular, podría convertirse gradualmente en una vía para construir la racionalidad ambiental. "La prospectiva ambiental implica así la desconstrucción de la racionalidad dominante y la construcción de una nueva racionalidad" (Leff, citado en Tréllez, 2002, p. 10). Los procesos de educación ambiental, con sus aportes al pensamiento crítico, se convierten en una vía para la construcción de futuros alternativos desde la visión de las relaciones sociedad-sociedad y sociedad-naturaleza. La alianza entre la prospectiva y la educación ambiental puede darnos una de las rutas para lograrlo (Tréllez, 2002).

Cuando hacemos uso de la noción de riesgo para observar un fenómeno como el cambio climático, lo convertimos en algo que no solo ha sido generado por la acción humana, sino que también puede evitarse mediante ella. Hablar de riesgo implica, pues, hablar de contingencia. Riesgo implica confrontarse con la construcción de futuros (Galindo, 2015).

Las orientaciones prospectivas de este estudio aluden a que los riesgos, y por lo tanto, las afectaciones de cualquier tipo provocadas por algún fenómeno natural, pueden prevenirse y ser enfrentadas con acciones responsables, siempre y cuando en la sociedad se promueva un pensamiento ambiental crítico, analítico y reflexivo. 


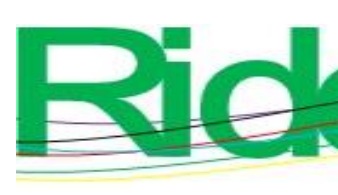

Revista Iberoamericana para la Investigación y el Desarrollo Educativo ISSN 2007-7467

\section{Antecedentes}

Estudios similares y relacionados con el presente hacen referencia a que los fenómenos naturales concluyen en desastres y que se vinculan con la vulnerabilidad de la zona y de las personas. Santiesteban, Castro, González y Sánchez (2010) realizaron un estudio durante la última semana del mes de noviembre de 2008, a tres meses de haber sido afectada la provincia de Pinar del Rio, Cuba, por los huracanes Gustav e Ike. La comunidad escogida para el estudio fue Bacunagua, que pertenece al municipio de Los Palacios, en el que se reportaron daños materiales de consideración y una localidad afectada. Rodríguez, Gelis y Fornaris (2013) establecieron que la región oriental de Cuba, a diferencia de la región occidental, ha sido azotada con menor frecuencia por tormentas tropicales y huracanes. La provincia Santiago de Cuba, por su posición geográfica, ubicada en el sureste de la isla de Cuba y en contacto con el mar Caribe, ha sido impactada por diferentes fenómenos, con resultados desastrosos por la alta vulnerabilidad de este territorio. Según Ramos (2009, citado en Rodríguez et al., 2013), "los desastres no son naturales, pues su origen está relacionado con la actividad del hombre" (p. 12). Entre ellos se encuentran los hidrometeorológicos extremos, como es el caso de los huracanes. El huracán Isidoro, que impactó la costa yucateca en septiembre de 2002, ocasionó que Chabihau quedara dividido en dos secciones por un brazo de agua que comunicaba el mar con la ciénaga; a ello se sumó la cantidad de agua en forma de lluvia que acompañó al huracán y que resultó en la inundación de una vasta zona de los manglares, los cuales se desbordaron y el agua excedente formó un amplio cuerpo sobre el puerto, Chabihau, y las carreteras que lo comunican con la cabecera municipal y los puertos vecinos. Numerosas viviendas sufrieron daños e incluso algunas fueron destruidas, al igual que plantaciones de cocoteros y decenas de embarcaciones (Guzmán y Rodríguez, 2016).

En el caso de México, debido a su ubicación, está expuesto a la ocurrencia de desastres naturales como sismos, inundaciones, sequías y heladas (Mansilla, citado en Ordóñez, Montes y Garzón, 2018). La institución gubernamental encargada de las iniciativas en educación ambiental es el Centro de Educación y Capacitación para el Desarrollo Sustentable (Cecadesu) de la Secretaría de Medio Ambiente y Recursos Naturales (Semarnat). México, a través de la Semarnat y de la Secretaría de Educación Pública (SEP), suscribió, en marzo del año 2005, un Compromiso Nacional por el Decenio de la Educación para el Desarrollo Sostenible. Fue el primer país en América Latina y el Caribe en implementar acciones en el marco del decenio (Oficina Regional de Educación para América 


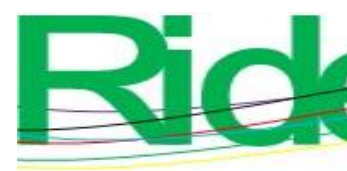

Revista Iberoamericana para la Investigación y el Desarrollo Educativo ISSN $2007-7467$

Latina y el Caribe [Orealc/Unesco Santiago], citada en Ordóñez et al., 2018). La misión de esta estrategia es establecer políticas públicas en el plano nacional y local en educación ambiental para la sustentabilidad que "favorezcan la construcción de una cultura ambiental, el incremento en la calidad de vida de la población, el fortalecimiento de la ciudadanía y de las múltiples identidades culturales del país, y la protección de los ecosistemas y su biodiversidad" (Semarnat, citada en Ordóñez et al., 2018, p. 9).

Las voces que conformaron este trabajo afirman que se han presentado diversas tormentas y huracanes en el municipio de San Marcos, Guerrero, y municipios vecinos como Acapulco, sin embargo, este último fue el que más sorprendió a los habitantes de dicha localidad, y principalmente a los habitantes de Las Vigas. Paulina, en 1997, es el que más recuerda la población. Si bien este fenómeno afectó a San Marcos, incluyendo la comunidad de Las Vigas, en Acapulco es donde se presentaron más afectaciones. El huracán Paulina impactó las costas del Pacífico mexicano, produjo pérdidas humanas y materiales (Toscana, 2003). Este huracán causó más desastres en el municipio vecino, Acapulco; en San Marcos, en la Costa Chica, los daños fueron menores. Otro huracán que impactó adversamente con inundaciones severas y otros daños fue la tormenta Henriette, en el 2007. Henriette tuvo impactos severos en Acapulco. Durante Henriette, el puerto de Acapulco reportó una lluvia intensa de $213.5 \mathrm{~mm}$, lo que ocasionó inundaciones en la costera Miguel Alemán y el deslizamiento de rocas que propiciaron el deceso de por lo menos seis personas (Hernández, 2007). La educación ambiental para la sustentabilidad es una estrategia necesaria para cimentar una cultura ambiental en la población que influya en la percepción del riesgo y medidas que se deben adoptar ante desastres provocados por fenómenos como huracanes.

La integración del enfoque de la gestión del riesgo en el sector educativo es determinante para incrementar la concientización sobre el efecto y causa de los desastres. Las escuelas que incluyen acciones de gestión del riesgo contribuyen a una cultura para la prevención, esencial para el desarrollo sostenible de los países. Estas acciones reducen los riesgos de desastres y fortalecen las capacidades de las comunidades más vulnerables para responder a las emergencias (Orealc/Unesco, citada en Ordóñez et al., 2018). Realmente, es importante el diseño e implementación de programas y proyectos apoyados en procesos educativos y de sensibilización que promuevan cambios de actitud en las personas y les permitan identificar, prevenir y actuar ante la ocurrencia de un fenómeno natural, minimizando la vulnerabilidad y afectación socioambiental (Ordóñez et al., 2018). 


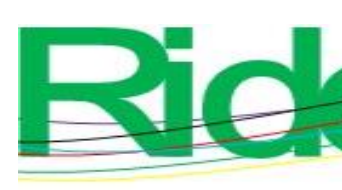

Revista Iberoamericana para la Investigación y el Desarrollo Educativo ISSN $2007-7467$

La intervención humana en la naturaleza ha generado impactos que afectan negativamente la integridad de los ecosistemas, de los cuales depende en gran parte el bienestar de la humanidad, y que, en algunos casos, han llegado a amenazar la integridad de la vida misma en nuestro planeta, tal como se evidencia de forma dramática con el calentamiento global (Rodríguez, 2007). El calentamiento global, según los investigadores, tiene muchas consecuencias, no solo para el planeta, sino también para los seres vivos que habitamos en él. Prueba de esto ha sido el constante cambio del clima, los fenómenos naturales que han llegado a afectar a una gran cantidad de personas alrededor del mundo, la mayoría de los casos a gente desprotegida (Fula y Ayala, 2007). Diversos estudios sugieren una mayor frecuencia de huracanes debido al calentamiento global y al aumento de las temperaturas de los océanos. Agua más caliente significa más energía disponible para los ciclones tropicales, la energía térmica se transforma en viento. Temperaturas más altas significan mayor evaporación, que, a su vez, conduce a una precipitación más intensa (Cárdenas, 2010). El calentamiento global altera las temperaturas del planeta, conduce al cambio de temperaturas, lo que comúnmente se conoce como cambio climático. El cambio climático global se refiere a las modificaciones en cualquier aspecto del clima del planeta, tales como la temperatura, precipitación e intensidad y las rutas de las tormentas (Miller, citado en Díaz, 2012).

Los efectos del cambio climático ya se están presentando: aquellos fenómenos climáticos, de gran intensidad y poca frecuencia, que tienen efectos ambientales y sociales adversos, ya sea regional o localmente. Ejemplo de ellos son los huracanes, tornados, sequías, heladas o granizadas. Las tormentas intensas que provocan inundaciones, así como pérdidas materiales y de vidas humanas (Semarnat, 2009). De acuerdo con Definición ABC (2010), una tormenta tropical es un fenómeno meteorológico característico de las zonas tropicales que evoluciona de un ciclón tropical y en el que los vientos son muy fuertes y abundantes lluvias. Los eventos climáticos extremos traen como consecuencia grandes pérdidas económicas, daños a la salud y, en muchos casos, desastres y fallecimientos (Murray y Murray, 2012). El bajo desarrollo social, así como el alto riesgo de las poblaciones, elevan la vulnerabilidad de la región ante el impacto de estos eventos. Por lo tanto, el abordaje de la dinámica propia de los ciclones tropicales debe estar ligado a los estudios de los impactos que estos provocan en la sociedad para entender bajo qué circunstancias sus efectos son mayores (Amador y Bonilla, citados en Alfaro, Quesada y Solano, 2011). 


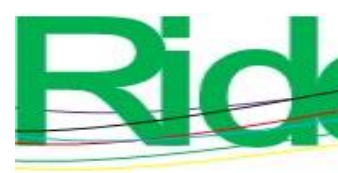

Revista Iberoamericana para la Investigación y el Desarrollo Educativo ISSN $2007-7467$

El paso del huracán Max por algunos municipios de la costa chica del estado de Guerrero, como es el caso de Las Vigas, afectó severamente a sus habitantes, principalmente a los que habitan en zonas vulnerables, en lo ambiental, en lo económico y lo social.

Las interrogantes que guiaron este trabajo son las siguientes:

- ¿Existe relación entre las actividades antropogénicas, la contaminación ambiental y los huracanes con los desastres que provoca?

- ¿Existe vulnerabilidad en los habitantes de Las Vigas en cuanto a la percepción social del riesgo ante huracanes y sus efectos?

- ¿Cuál fue el impacto ambiental, económico y social que causó la inundación, las fuertes lluvias y otras afectaciones del huracán Max en habitantes de Las Vigas?

- ¿La educación para el desarrollo sustentable permite fomentar los conocimientos, habilidades, valores en la población sobre la preservación del medio y así desarrollar estrategias de percepción del riesgo, prevención y mitigación ante la presencia de huracanes y sus efectos que causa?

\section{Objetivo}

El objetivo de este trabajo fue analizar el impacto ambiental, económico y social que sufrió la población afectada por el huracán Max. Asimismo, determinar las causas y efectos que causó la inundación y, con ello, determinar medidas de prevención y mitigación ante afectaciones que puedan ocurrir por un evento similar en un futuro con apoyo de la cultura de la prevención del riesgo y de la educación ambiental para la sustentabilidad.

\section{Justificación teórica}

Este estudio se fundamentó con los supuestos del desarrollo sustentable, la percepción del riesgo y la educación ambiental para la sustentabilidad. La sustentabilidad hace alusión a un fuerte vínculo entre medio ambiente y otros aspectos como el social y el económico. La percepción del riesgo se enfoca en explicar la percepción cognitiva ante las amenazas que pueden presentar un riesgo. La población, en algunos casos, no cuenta con una cultura de percepción, por lo que son aún más vulnerables a los efectos producidos por los fenómenos naturales. En cuanto a la educación ambiental para la sustentabilidad, se encarga de promover conocimientos, habilidades y valores en las personas para ser responsables en el cuidado y preservación y ser capaces de relacionar la temática de medio ambiente con tópicos 


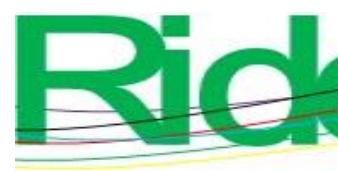

Revista Iberoamericana para la Investigación y el Desarrollo Educativo ISSN $2007-7467$

sociales como es lo económico y lo social para coadyuvar de igual manera en la sustentabilidad que se requiere alcanzar.

Las afectaciones producidas por huracanes causan afectaciones económicas en las personas que resultan afectadas, debido a que sufren pérdidas de varios tipos, entre ellas de bienes materiales. El Gobierno en sus tres ámbitos, municipal, estatal y federal, activa sus protocolos de emergencia para atender a la población y a la infraestructura que sufrió afectaciones. Esto último repercute en el estancamiento del desarrollo sustentable. Quiroz, del Amo y Ramos (2011) definen al desarrollo como un concepto que se utiliza en todas las esferas y países y cuyo primer significado es 'crecimiento, cambio o mejora en un determinado periodo' y emplean la palabra sustentabilidad para calificar el desarrollo y el crecimiento económico, especialmente referido a los países en vías de desarrollo, sensibles a los problemas ambientales. El concepto de desarrollo sostenible es el resultado de la creciente percatación de los vínculos globales entre problemas ambientales y cuestiones socioeconómicas. Vincula fuertemente al medio ambiente y las cuestiones socioeconómicas (Hopwood, Mellor y O’Brien, 2005).

El hombre sigue afectando la naturaleza y el medio ambiente, contaminando los suelos, contaminando aguas, haciendo uso irracional de químicos, deforestando zonas, destruyendo ecosistemas, afectando la biodiversidad, residuos sólidos en el ambiente y otras prácticas y aspectos que se pueden adherir, tal y como actos de corrupción, concesiones para edificaciones en zonas no aptas para la construcción, por ejemplo, zonas de conservación, tráfico de animales, sobrepoblación, entre otros; todo ello está influyendo en el deterioro ambiental y es la razón por la que no se da un desarrollo sustentable equitativo. Los fenómenos hidrometeorológicos son de tipo natural, sí, sin embargo, la intensidad de ellos se asocia con las problemáticas desmedidas que realiza el hombre sobre el medio ambiente. Las afectaciones y desastres que llegan a provocar impactan en el desarrollo sustentable de una comunidad y, por ende, de sus habitantes de varias maneras: en lo económico, lo social, la salud, etc.

En cuanto a la percepción de la población sobre los fenómenos hidrometeorológicos y sus repercusiones en el ámbito social y personal, es de suma importancia que las personas desarrollen procesos cognitivos ante las repercusiones y afectaciones sociales que pudieran producirse por eventos naturales. En las investigaciones cualitativas, es imprescindible la opinión y los detalles provenientes de los procesos cognitivos sobre la imagen y representación que tienen los sujetos sobre algo. La psicología define, en términos generales, 


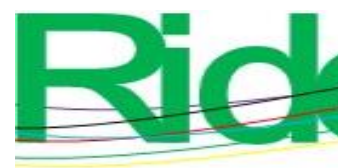

Revista Iberoamericana para la
Investigación y el Desarrollo Educativo
ISSN $2007-7467$

denominó sociedad del riesgo es, hoy día, el escenario de la crisis ambiental. El construir conocimiento y ayudar a la emergencia de un pensamiento ambiental orientador es, sin duda, un gran desafío (Beck, citado en Novo, 2005).

En lo que respecta a la educación ambiental para la sustentabilidad, su labor es fundamental en el desarrollo de conocimientos, habilidades, actitudes y valores en la población para que formen un sentido responsable para cuidar y preservar el medio, teniendo en cuenta que su cuidado y protección contribuye en la sustentabilidad que se desea alcanzar. Desde sus inicios, la educación ambiental pretende promover actitudes de curiosidad, respeto y valoración hacia todos los componentes del patrimonio natural. Muy pronto amplía su campo de acción al conjunto de los problemas ambientales (contaminación, aglomeraciones urbanas, consumo, residuos, cambio climático, etc.), incluyendo los aspectos socioeconómicos (años 80), pero se mantiene próxima a los mecanismos que rigen los ecosistemas naturales y sigue pregonando el valor e interés afectivo y formativo del contacto con la naturaleza (Alcántara y Bourrut, 2006). La Organización de las Naciones Unidas para la Educación y Diversificación, la Ciencia y la Cultura [Unesco] (2005) manifiesta que la educación para el desarrollo sostenible permite que cada ser humano adquiera los conocimientos, las competencias, las actitudes y los valores necesarios para forjar un futuro sostenible. Educar para el desarrollo sostenible significa incorporar los temas fundamentales del desarrollo sostenible a la enseñanza y el aprendizaje, por ejemplo, el cambio climático, la reducción del riesgo de desastres, la biodiversidad, la reducción de la pobreza y el consumo sostenible.

\section{Método}

\section{Tipo de estudio}

Este estudio empleó el paradigma cualitativo para su realización. En la investigación cualitativa existen diferentes técnicas de colecta de datos, cuyo propósito principal es obtener información de los participantes fundamentada en las percepciones, las creencias, las opiniones, los significados y las actitudes, por lo que la entrevista es una valiosa técnica (Vargas, 2012). De entre las técnicas para recabar información de la población, la seleccionada fue la entrevista no estructurada. La entrevista no estructurada puede proveer una mayor amplitud de recursos con respecto a los otros tipos de entrevista de naturaleza cualitativa. Según del Rincón (citado en Vargas, 2012), quien habla respecto a este tipo de 


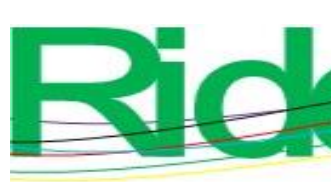

Revista Iberoamericana para la Investigación y el Desarrollo Educativo ISSN 2007-7467

técnica, el esquema de preguntas y secuencia no está prefijada; las preguntas pueden ser de carácter abierto y el entrevistado tiene que construir la respuesta; son flexibles y permiten mayor adaptación a las necesidades de la investigación y a las características de los sujetos, aunque requiere de más preparación por parte de la persona entrevistadora, la información es más difícil de analizar y requiere de más tiempo. La documentación bibliográfica fue fundamental para la descripción del análisis. Este estudio se realizó en el año 2017.

\section{Población y muestra}

La localidad de Las Vigas pertenece al municipio de San Marcos, Guerrero, México. Según el Catálogo de Localidades de la Secretaría de Desarrollo Social [Sedesol] del año 2013, el grado de marginación de la localidad hasta el año 2010 era muy alto, la clave de la localidad es 0067 y el nombre es Las Vigas. Se estipula, también, que en el año 2005 se contaba con una población de 4296 habitantes, de los cuales 2026 eran hombres y 2270 mujeres. En el año 2010, se contó con 4504 habitantes, de los cuales 2187 eran hombres y 2317 mujeres. En el 2005, se contaba con 988 viviendas ocupadas y en el 2010, con 1082. El grado de rezago social de la comunidad es bajo en los dos periodos y existe carencia en las viviendas debido a que muchas de ellas presentan carencias de acceso a servicios básicos. En el 2005, 355 (36.49\%) no tenían drenaje; en el 2010 fueron 174 (16.14\%). En el 2005, 23 $(2.33 \%)$ no contaban con el servicio de energía eléctrica; en el 2010 ya solo $3(0.28 \%)$. Respecto a las viviendas sin agua entubada, en el 2005 fueron 167 (17.15\%) y en 2010 fueron $239(22.21 \%)$. Y en cuanto a viviendas sin sanitario, en el 2005 fueron 283 (28.64 \%) y en el 2010, $177(16.36 \%)$.

Figura 1. Las Vigas Municipio de San Marcos Guerrero en el contexto nacional

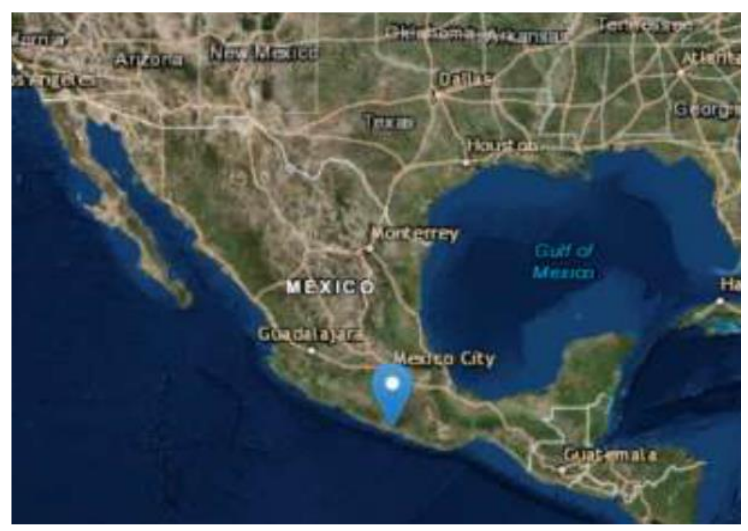

Fuente: PueblosAmerica.com (s. f.) 


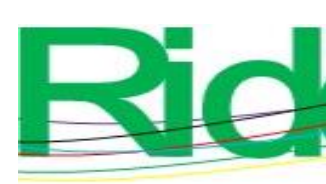

Revista Iberoamericana para la Investigación y el Desarrollo Educativo ISSN $2007-7467$

\section{Técnicas e instrumentos empleados}

Se revisó en fuentes oficiales la trayectoria del huracán para determinar su recorrido y el punto o comunidad donde tocó tierra. Para ello, se consultó en la página oficial de la Comisión Nacional del Agua [Conagua) (2017). Esta información fue necesaria para determinar la distancia que existe de la comunidad de Las Vigas y donde fue el ojo del huracán.

Se aplicó una entrevista no estructurada a las personas que compusieron la muestra de este estudio. En relación con la entrevista, aunque fue no estructurada, se contó con un guion, es decir, se respetaron las variables consideradas y dimensiones en lo que concierne a lo ambiental, económico, social y la cultura y percepción de riesgo. El procedimiento para analizar la entrevista fue a través de un análisis cualitativo por cada dimensión. Finalmente, se empleó el método de la descripción para presentar resultados.

Tabla 1. Operacionalización de variable para la entrevista no estructurada a los habitantes afectados por el paso del huracán Max en Las Vigas, Guerrero

\begin{tabular}{|c|c|c|c|c|}
\hline Categoría & Variable & Dimensión & Indicador & $\begin{array}{l}\text { Instrumento (entrevista } \\
\text { estructurada y no } \\
\text { estructurada). } \\
\text { Preguntas realizadas }\end{array}$ \\
\hline \multirow[t]{2}{*}{$\begin{array}{l}\text { Aspecto medio } \\
\text { ambiente }\end{array}$} & $\begin{array}{l}\text { Residencia en la } \\
\text { calle o colonia. } \\
\text { Nivel } \\
\text { socioeconómico } \\
\text { y cultural. }\end{array}$ & $\begin{array}{l}\text { Pobladores } \\
\text { oriundos y } \\
\text { recientes. }\end{array}$ & Tiempo. & $\begin{array}{l}\text { ¿Cuánto tiempo lleva } \\
\text { radicando en este lugar? } \\
\text { ¿Desde cuándo se } \\
\text { percató que las lluvias } \\
\text { fuertes causan } \\
\text { afectaciones? } \\
\text { Ocupación, nivel escolar, } \\
\text { vivienda, ingresos. }\end{array}$ \\
\hline & $\begin{array}{l}\text { Causas de las } \\
\text { afectaciones. }\end{array}$ & $\begin{array}{l}\text { Característica } \\
\text { s del terreno. }\end{array}$ & Suelo. & $\begin{array}{l}\text { ¿Qué cree usted que } \\
\text { causó la inundación? }\end{array}$ \\
\hline
\end{tabular}




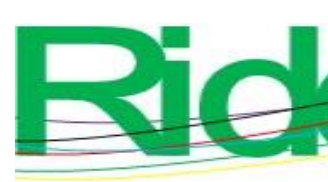

Revista Iberoamericana para la Investigación y el Desarrollo Educativo ISSN 2007 - 7467

\begin{tabular}{|c|c|c|c|c|}
\hline & $\begin{array}{l}\text { Percepción del } \\
\text { huracán Max en } \\
\text { la comunidad de } \\
\text { Las Vigas. }\end{array}$ & $\begin{array}{l}\text { Lluvias en la } \\
\text { zona. }\end{array}$ & $\begin{array}{l}\text { Intensidad de la } \\
\text { lluvia. }\end{array}$ & $\begin{array}{l}\text { ¿Cómo percibió las } \\
\text { lluvias originadas por el } \\
\text { huracán Max? }\end{array}$ \\
\hline $\begin{array}{l}\text { Aspecto } \\
\text { económico }\end{array}$ & $\begin{array}{l}\text { Afectación } \\
\text { económica. }\end{array}$ & $\begin{array}{l}\text { Pérdida de } \\
\text { bienes } \\
\text { materiales. }\end{array}$ & $\begin{array}{l}\text { Encharcamientos } \\
\text { Camino, carretera, } \\
\text { casa, etc. } \\
\text { Electrodomésticos, } \\
\text { animales, muebles, } \\
\text { etc. }\end{array}$ & $\begin{array}{l}\text { ¿Qué problemas } \\
\text { económicos presentó por } \\
\text { las afectaciones } \\
\text { producidas durante el } \\
\text { huracán Max? }\end{array}$ \\
\hline Aspecto social & $\begin{array}{l}\text { Afectación } \\
\text { social. }\end{array}$ & $\begin{array}{l}\text { Salud. } \\
\text { Servicios } \\
\text { públicos. } \\
\text { Solidaridad } \\
\text { social. }\end{array}$ & $\begin{array}{l}\text { Enfermedades. } \\
\text { Servicio de luz, } \\
\text { agua y telefonía } \\
\text { Despensa familiar } \\
\text { Apoyo } \\
\text { gubernamental, de } \\
\text { instituciones y } \\
\text { particulares. }\end{array}$ & $\begin{array}{l}\text { ¿Presentó algún } \\
\text { problema en cuestión de } \\
\text { salud, en los servicios } \\
\text { públicos como luz, agua, } \\
\text { teléfono y abastecimiento } \\
\text { de productos de la } \\
\text { canasta básica? } \\
\text { ¿Recibió apoyos por } \\
\text { parte del Gobierno, de } \\
\text { alguna institución o de } \\
\text { algún particular? }\end{array}$ \\
\hline $\begin{array}{l}\text { Percepción del } \\
\text { riesgo y } \\
\text { Educación } \\
\text { Ambiental } \\
\text { para } \\
\text { Sustentabilidad }\end{array}$ & $\begin{array}{l}\text { Aplicación de } \\
\text { estrategias ante } \\
\text { fenómenos } \\
\text { hidrometeorológ } \\
\text { icos y sus } \\
\text { afectaciones o } \\
\text { desastres. }\end{array}$ & $\begin{array}{l}\text { Percepción } \\
\text { de riesgos } \\
\text { ante } \\
\text { amenazas y } \\
\text { las } \\
\text { afectaciones } \\
\text { que pueden } \\
\text { ocurrir. }\end{array}$ & $\begin{array}{l}\text { Medidas a tomar en } \\
\text { caso de presentarse } \\
\text { un fenómeno } \\
\text { natural como lo es } \\
\text { un huracán } \\
\text { Afectación al } \\
\text { medio ambiente y } \\
\text { adquisición de } \\
\text { saberes } \\
\text { ambientales }\end{array}$ & $\begin{array}{l}\text { ¿Cómo percibe usted la } \\
\text { presencia de un } \\
\text { huracán?, ¿qué medidas } \\
\text { conoce e implementa? }\end{array}$ \\
\hline
\end{tabular}




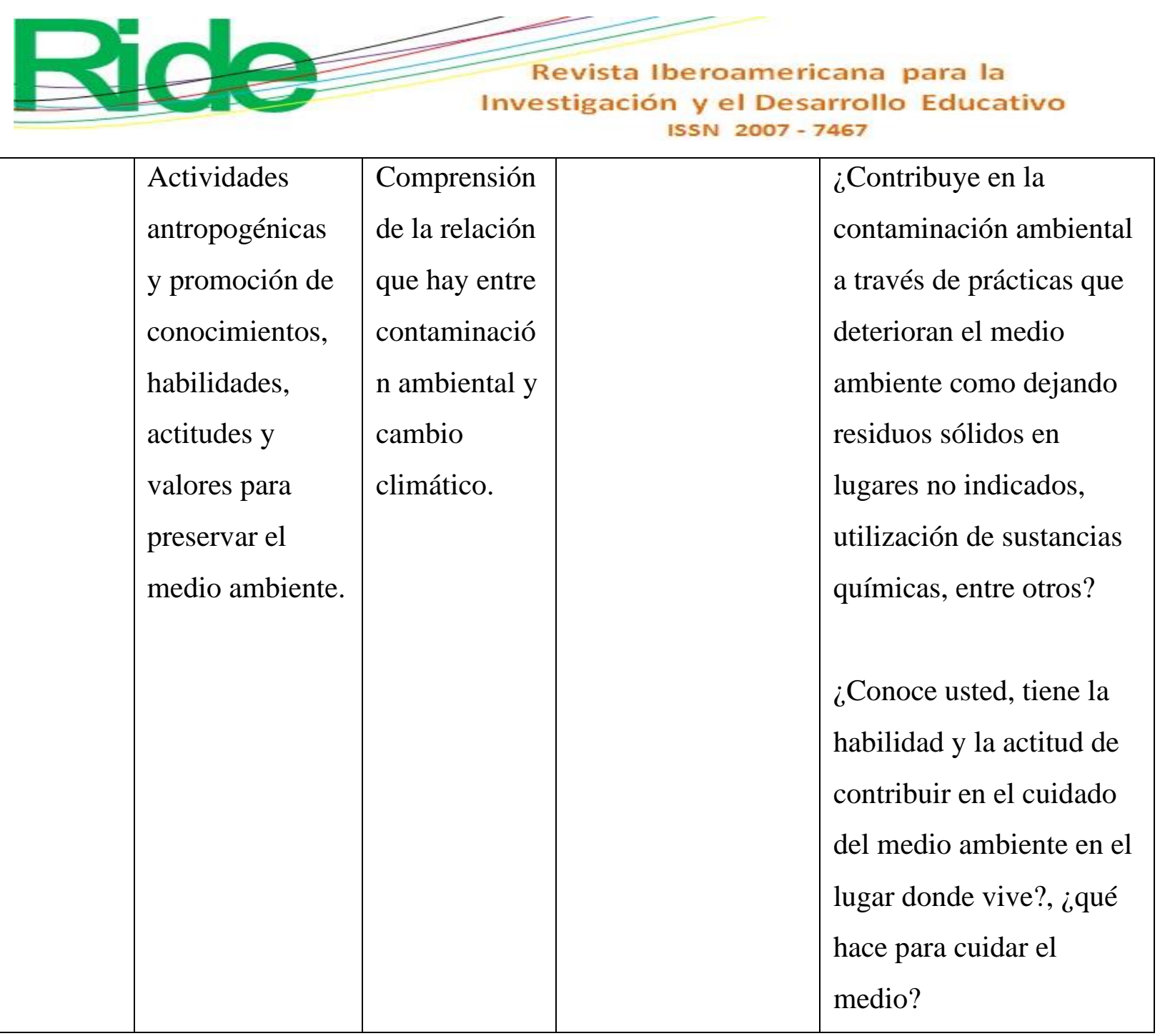

Fuente: Elaboración propia

\section{Resultados}

De acuerdo con la Conagua (2017), el huracán Max del Océano Pacífico se desarrolló entre el 13 y 15 septiembre de 2017. El día 13 de septiembre a las 10:00 horas se formó la depresión tropical 16-E a $165 \mathrm{~km}$ al sur de Zihuatanejo, Gro., y a $205 \mathrm{~km}$ al oeste-suroeste de Acapulco, Gro., con vientos máximos sostenidos de $55 \mathrm{~km} / \mathrm{h}$, con un desplazamiento hacia el nor-noreste a $7 \mathrm{~km} / \mathrm{h}$ y presión mínima central de $1006 \mathrm{hPa}$. El sistema favoreció potencial de lluvias, vientos fuertes y oleaje elevado sobre Michoacán, Guerrero y Oaxaca. Los antecedentes de la depresión en cuestión, según este organismo, se formaron a $300 \mathrm{Km}$ al sur de Puerto Ángel, Oax. lo cual se le dio seguimiento desde el 10 de septiembre a las 19:00 horas y hasta el día 13 de julio a las 07:00 horas. A las 16:00 horas, del 13 de septiembre la depresión tropical 16-E se desarrolló a tormenta tropical con el nombre de Max, con vientos máximos sostenidos de $65 \mathrm{~km} / \mathrm{h}$ y rachas de $85 \mathrm{~km} / \mathrm{h}$, ubicándose a $170 \mathrm{~km}$ al sur de Zihuatanejo, Gro., y a $185 \mathrm{~km}$ al oeste-suroeste de Acapulco, Gro. El día 14 de septiembre, a las 7:00 horas, Max se intensificó y se convirtió en huracán categoría uno en la escala de 


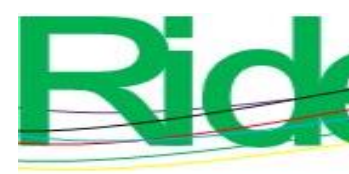

\section{Revista Iberoamericana para la Investigación y el Desarrollo Educativo ISSN 2007 - 7467}

Saffir-Simpson, muy cerca de la costa de Guerrero, a $85 \mathrm{~km}$ al suroeste de Acapulco. Aproximadamente a las 16:00 horas del mismo día, el ojo del huracán Max categoría uno impactó sobre la línea de costa en las cercanías de la población de Pico del Monte, al sur de Laguna de Chautengo, Gro., a $15 \mathrm{~km}$ al oeste de Copala, Gro., y a $90 \mathrm{~km}$ al este-sureste de Acapulco, Gro.

La distancia en tiempo que existe entre la comunidad de Las Vigas del municipio de San Marcos y la comunidad de Pico del Monte, en el municipio vecino de Florencio Villarreal, es de aproximadamente 20 minutos por carretera. Por este hecho los efectos fueron similares $\mathrm{y}$, por consiguiente, las intensas lluvias, aires e inundaciones provocaron afectaciones ambientales y, en algunos casos, afectaciones económicas y sociales en habitantes que habitan zonas vulnerables, como lo fue con las personas de la comunidad de Las Vigas.

\section{Variable socioeconómica y medio ambiente: "Radicación en el lugar, nivel socioeconómico, percepción de lluvias fuertes y causas de la inundación"}

Se aplicó una entrevista a 100 personas de edad adulta. En su mayoría, eran amas de casa, agricultores o trabajadores del campo, algunos jóvenes que ocupan su tiempo en alguna labor, hubo algunos comerciantes, algunos (mínima parte) profesionistas; algunas personas sin nivel escolar, otros con grados de primaria, secundaria y hasta prepa. Algunas viven en casas de material, otras en casas de adobe u otro material. Algunos domicilios de los entrevistados cuentan con servicio de drenaje y luz; en otros el servicio de drenaje es irregular. Esta información tiene relación con el Catálogo de Localidades de la Sedesol (2013), en donde se manifiesta que el grado de rezago social de la comunidad es bajo.

Las personas entrevistadas en su mayoría comentaron que son oriundos de la comunidad de Las Vigas; muy pocos dijeron que habían llegado de otro lugar: algunos que ya tenían algunos años, otros que su llegada era reciente. Las personas entrevistadas habitan en las colonias o lugares populares conocidos como El Aterrizaje, la Tabiquería, la colonia Santa Cruz (calle Niño Perdido), La Dicha (Centro), Canal, El Charco y El Tanque, estos fueron los lugares donde se presentaron con más fuerza las afectaciones. La mayoría contestó que fue la primera vez que un huracán o lluvias fuertes causaron afectaciones y en su mayoría inundaciones; hubo algunas personas que comentaron que en huracanes anteriores sí se habían presentado lluvias, pero no tan fuertes como las registradas durante el paso de Max. Asimismo, sí había habido inundaciones, pero no de esta magnitud. Algunos recuerdan las 


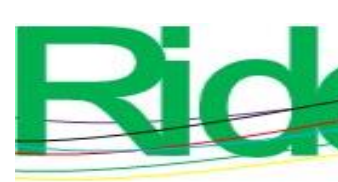

Revista Iberoamericana para la
Investigación y el Desarrollo Educativo
ISSN $2007-7467$

afectaciones provocadas por las lluvias de Paulina, en 1997, sin embargo, comentaron que fueron de menor proporción.

En lo que respecta a las causas de la inundación, comentaron que fueron de manera natural, porque eran épocas de lluvias; sin embargo, antes llovía en junio, julio y agosto, ya en septiembre las lluvias eran menos. En los últimos años, parece que el tiempo ha cambiado, ahora las lluvias son en septiembre, octubre y noviembre. Los desastres que dejó el huracán fue porque llovió y el aire era muy fuerte. Por mucha agua, los caminos y carreteras se inundaron, se volvieron ríos y arrastró basura, lodo, provocó encharcamientos, socavones, derribó puentes, como el de San Marcos. Los ríos y arroyos se desbordaron porque llovió mucho; así fue con el río de San Marcos y el arroyo de Las Vigas, cuyas aguas llegaron a inundar las colonias del pueblo. Las causas de afectación en los caminos y carreteras se dan porque las autoridades no dan mantenimiento a las vías de comunicación. En Las Vigas, las personas tiran sus desechos en canales, charcos, arroyo del pueblo; además, la maleza crece a sus alrededores. No se hace algo para mantener limpia esta área. No existe un lugar o espacio indicado destinado para que las personas lleven sus desechos y la mayoría de las colonias las desechan en sus alrededores, ejemplo de ello, en la colonia Santa Cruz, en La Parota. Algunos comentaron que saben que hay un relleno sanitario por el lado del Sepudo, lugar perteneciente a la comunidad en cuestión, pero, aun así, hay personas que no llevan sus residuos allí porque está algo retirado, por lo tanto, prefieren llevarla a las orillas del pueblo. El Charco, cuerpo de agua ubicado en la colonia que lleva este nombre, sirve de depósito de residuos, animales muertos y otros desechos en sus orillas, sobre todo cuando es temporada de secas y los niveles de agua están al mínimo. Aparte de estar azolvado, no tiene desagüe, es decir, el agua no tiene salida, se represa y en las lluvias esto provoca su desborde. Con respecto al arroyo Las Vigas, también en las secas disminuye y en las orillas y en la parte de adentro se pueden observar residuos de distintos tipos. Está azolvado, la maleza crece en sus inmediaciones y dentro de este. Sus arenas han sido removidas por habitantes y personas externas que obtienen un beneficio. A simple vista, se observa que la arena ha desaparecido y en su lugar ha quedado lodo o montañas de tierra acumulada, lo que genera obstrucciones de fluidas de agua, lo cual, a su vez, en tiempos de lluvias, implica riesgo por la salida de sus aguas. Lo que ocasionó el desborde y, por ende, su salida hacia las colonias vecinas al pueblo, no solamente fueron las fuertes lluvias, sino lo que las personas llevan a cabo al afectar este recurso natural. 


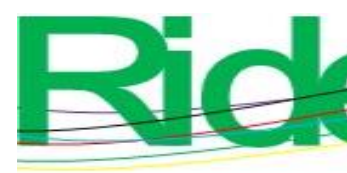

Revista Iberoamericana para la
Investigación y el Desarrollo Educativo
ISSN $2007-7467$

En relación con el canal de riego que atraviesa las orillas de la comunidad de Las Vigas, está azolvado severamente, crece la maleza y la basura se acumula. Además, está cancelado o tapado por completo en algunos tramos. Los entrevistados comentaron que el agua fue entubada en un tramo que atraviesa Las Vigas, el entubamiento hizo posible que los canales fueran cancelados y se llenaran los espacios con tierra y escombros y, por lo tanto, la característica del terreno sufrió modificaciones. En algunas otras partes, el entubamiento fue a un costado de este, dejando los canales para que el agua fluyera, sin embargo, estos han sido llenados con escombros y desechos que las personas de la comunidad llevan a depositar. Con los rellenos de tierra y escombro que se realizaron cuando se entubó el agua del canal, los cauces que se habían dejado para que el agua fluyera fueron cerrados. Estos rellenos han causado que el agua no ingrese a los canales y los topes provocaron el alzamiento y el regreso del agua hacia los domicilios de las colonias afectadas. Algunas personas comentan que personal de la Conagua dice a los habitantes que los canales de riego no fueron hechos para dar fluidez al agua y que entre a Las Vigas, sino que fueron para regar las parcelas de sembradíos de los campesinos, sin embargo, el canal tenía cauces y estos fueron cancelados. Las aguas que se acumulan en la colonia El Panteón se acumulan y finalmente fluyen por canales que conducen al arroyo de la dicha que recorre la calle Plan de Ayala (mercado, Primaria Federal Benito Juárez, hasta llegar al canal). El desemboque de este arroyo también fue clausurado y estas aguas residuales se reparten entre las zonas aledañas al canal.

\section{Variable económica: "Pérdida de bienes materiales a causa de las inundaciones y fuertes lluvias"}

En lo que respecta a pérdidas materiales, algunos afectados expresaron que los que tienen huertas o parcelas de siembra les fueron arrebatados árboles debido a los fuertes vientos y corrientes de agua. Entre esos árboles se mencionan los limones, mangos y palmeras. Además, algunas personas que tenían cocos para (su venta) los perdieron también por las fuertes corrientes. Todos los entrevistados comentaron que tuvieron pérdidas materiales en sus pertenencias, por ejemplo, muebles y objetos de línea blanca (refrigeradores, lavadoras, camas, salas, colchones, camas, etc), entre otros. Hay personas que perdieron animales que tenían para la crianza: marranos, gallinas, patos, guajolotes y vacas, así como perros, gatos y caballos. 


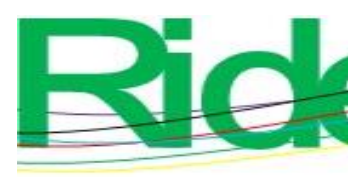

Revista Iberoamericana para la Investigación y el Desarrollo Educativo ISSN $2007-7467$

Todos manifestaron que el huracán Max trajo mucha lluvia, demasiada. Que han pasado otros huracanes pero que este se sintió fuerte. Las calles se llenaron de agua en niveles considerables. También comentaron que hizo mucho aire, lo denominaron ventarrón. La lluvia fuerte y el aire juntos provocaron devastaciones en los caminos y dañaron los servicios, el telefónico, el agua potable, la electricidad, etc.; ello implicó que personas que tenían negocios se les echaran a perder sus productos. Las lluvias de Max provocaron inundaciones en varias partes del pueblo, aunque hubo colonias que resintieron más, donde los niveles de agua llegaron casi a cubrir las casas: la colonia El Charco, en la colonia Santa Cruz, El Aterrizaje, en el Centro, por la calle del mercado (la zona conocida como La Dicha), también por la zona del Panteón y la secundaria (cercanas al arroyo). Las inundaciones provocaron daños en las estructuras de las viviendas y las pertenencias que se encontraban dentro. Algunas personas declararon que las fuertes corrientes les arrebataron dinero en efectivo que tenían guardado en sus casas y otros objetos de valor. Hubo caminos (carreteras) incomunicados: de Las Vigas a San Marcos, a Acapulco; y de Las Vigas a Cruz Grande. El nivel de agua hizo vulnerable la carretera. Se inundaron, se trozaron, también cayeron árboles que impedían el paso, así que el comercio se detuvo por completo. Algunos entrevistados dijeron que las pérdidas en todos los ámbitos fueron materiales y que no se presentaron pérdidas de vidas humanas, al menos en la comunidad de Las Vigas.

\section{Variable social: "Salud, servicios públicos, solidaridad social"}

En cuestión de salud, algunas personas fueron afectadas física y psicológicamente. En términos específicamente físicos, se presentaron enfermedades de la piel, ronchas y sarpullidos, además de resfriados. Se dio también la proliferación de moscos (Aedes aegypti). En cuestión de salud emocional, muchas personas presentaron pánico por las lluvias (no dormían pensando en que, si llovía, les iba a llegar el agua); acudían a dormir a lugares que no fueron afectados por completo. También muchos lloraron y lamentaron las pérdidas que tuvieron, no asimilaban haber perdido todo lo que lograron en años atrás en cuestión de horas.

Otros problemas que se presentan con las lluvias fue la falta de servicio de agua. Todo el año es irregular y en épocas de lluvias se corta por completo. Igualmente, el servicio de energía eléctrica, que dura días para que se restablezca y la Comisión Federal de Electricidad (CFE) tarda en aparecer para dar solución a este servicio, no obstante, el pago del servicio es puntual. Por último, la televisión, el internet, el teléfono, fallan al no contar con luz eléctrica y esto impide la comunicación con familiares en situaciones de desastres. 


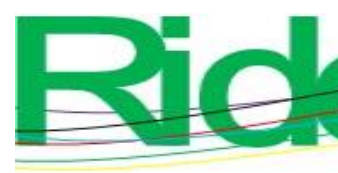

Revista Iberoamericana para la
Investigación y el Desarrollo Educativo
ISSN $2007-7467$

Durante el paso del huracán, con las inundaciones, la sociedad civil fue la que se organizó para rescatar a las personas de sus viviendas. Grupos de la comunidad entre vecinos, familiares y amigos apoyaron para sacar a las personas de sus casas inundadas y llevarlas a lugares seguros. Después del fenómeno, se percibió todavía el desastre: casas inundadas, con lodo, sin muebles, sin ropa, con electrodomésticos descompuestos, animales muertos; muchas personas perdieron sus pertenencias (ropa, despensa, dinero, etc.), se las llevó la corriente y las que quedaron estaban inservibles; no había servicio de luz, de teléfono, internet; la comida escaseó, las tortillas escasearon al no haber luz y la leña, mojada; sin agua potable; no se podían trasladar las personas a la cabecera municipal porque las carreteras estaban incomunicadas. En ese momento, la gente pidió ayuda a gritos. La comunidad resintió esta situación por más de 15 días. Con el paso del tiempo se fue normalizando la situación, sin embargo, hay familias que tardaron más en superar ese momento.

A partir del segundo día y hasta casi un mes después estuvo llegando la ayuda (despensas, ropa, colchones, camas, agua embotellada y apoyos económicos para las familias más vulnerables y que habían perdido sus bienes por completo). Esta ayuda llegó de las aportaciones de grupos de la sociedad civil, del Gobierno y de algunas organizaciones o instituciones. En el caso del Gobierno, el Sistema Nacional para el Desarrollo Integral de la Familia (DIF) apoyó con algunas despensas y ropa. Algunos entrevistados comentaron que Protección Civil les apoyó con material de limpieza, aunque otros mencionaron que no se dieron cuenta. Muchas personas y grupos de la sociedad civil apoyaron con despensas y ropa a los afectados. Los paisanos que están en Estados Unidos se organizaron y apoyaron con recursos económicos a las familias que perdieron todo. Una institución que apoyó en todo momento fue la Iglesia, a través de su sacerdote, quien apoyó en cuestiones psicológicas, también en gestionar ropa, despensas, colchones, etc. Otras instituciones que apoyaron fueron las escuelas. Las escuelas de la Universidad Autónoma de Guerrero acudieron a brindar apoyo con despensas, ropa y servicio médico. Otras escuelas apoyaron, no obstante, los participantes no lograron recordar el nombre. 


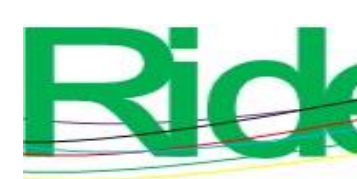

Revista Iberoamericana para la Investigación y el Desarrollo Educativo ISSN 2007 - 7467

\section{Variable: "Percepción del riesgo y educación ambiental para sustentabilidad"}

Los entrevistados comentaron que no están preparados ni organizados ante una contingencia como la que se presentó con el huracán Max. Comentaron que no es justo perder todo de la noche a la mañana, todo su ahorro, todo lo que han comprado a base de su trabajo para que ocurra un desastre y se lo lleve en cuestión de horas. Sin embargo, agradecen que el fenómeno que llevó a esta situación fue en horarios donde la gente estaba despierta, de lo contrario hubiera sido una catástrofe mayor, porque muchas personas se hubieran ahogado, porque las corrientes hubieran sorprendido y, sin luz eléctrica, no hubieran visto para dónde caminar o salir. Consideran que esto que ocurrió los lleva a pensar y replantear la situación y que deben organizarse. Sugieren identificar las causas del asunto de fondo, y se preguntan “¡por qué antes esto no se daba cuando se presentaba un huracán o las lluvias eran intensas?”. Comentan que en la comunidad hay una dependencia de la Conagua y que deben de solicitar una explicación por lo sucedido, ya que consideran que las lluvias afectaron el pueblo por algunas obras que ellos realizaron; por tal motivo, es necesario integrar un comité integrado por habitantes de las colonias que fueron afectadas. Relataron también que los flujos y cuerpos de agua como el arroyo y el charco próximos a la comunidad influyeron en la inundación porque fueron los que se desbordaron, a pesar de ello, siempre han estado y sus aguas nunca han llegado hasta las colonias como ahora; hubo algunas personas que comentan que en torrenciales pasados sí se habían desbordado el arroyo y el charco, pero no como ahora. Existe una carencia sobre la cultura del riesgo en el sentido de que se desconocen las medidas para hacer frente a situaciones de desastres provocadas por lluvias intensas y por inundaciones al paso de un fenómeno natural. La comunicación de los riesgos ambientales es necesaria y debe brindarse a la comunidad como medida de prevención y mitigación de daños de varios tipos. No se refleja una coordinación entre ciudadanos e instituciones responsables que alerten a la población para estos fines.

Aunado a la insuficiente percepción del riesgo, se considera fundamental la promoción de una cultura ambiental con programas, cursos o talleres sobre educación ambiental para la sustentabilidad, con temáticas encaminadas a la percepción del riesgo, problemáticas ambientales, desastres causados por inundaciones, cambio climático, calentamiento global, gases de efecto invernadero, fenómenos hidrometeorológicos, para que los habitantes de las comunidades, a través de perspectivas no formales de la educación ambiental, formen conocimientos, habilidades y valores para el cuidado y preservación de su entorno. Algunas acciones que competen a la educación ambiental sustentable y que 


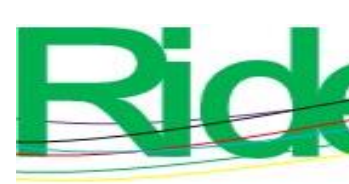

Revista Iberoamericana para la Investigación y el Desarrollo Educativo ISSN 2007 - 7467

ambiente natural (Blaikie, citado en Angelotti, 2014). Las lluvias intensas y el fortalecimiento del huracán Max fueron percibidos por toda la comunidad y principalmente por los habitantes de las colonias seleccionadas. El huracán Max fue muy fuerte y trajo mucha agua, a tal grado de que compararon huracanes de años anteriores con este y concluyeron que antes no habían tenido tantas afectaciones como ahora. Muchas personas no comprenden aún que los seres humanos son los que alteran las condiciones del clima con las acciones dañinas que causan al entorno. La modificación del clima implica aumentar o bajar temperaturas, lo que influye en que se presenten sequías o lluvias intensas y demás.

La intervención humana en la naturaleza ha generado impactos que afectan negativamente la integridad de los ecosistemas (Rodríguez, 2007). Diversos estudios sugieren una mayor frecuencia de huracanes debido al calentamiento global (Cárdenas, 2010). En la comunidad objeto de estudio, el huracán Max trajo afectaciones y desastres, daños en la infraestructura e interrupción de servicios básicos. Asimismo, la población sufrió en lo ambiental, en lo económico y en otros aspectos sociales. Estas afirmaciones también son similares con los resultados de estudios realizados por Santiesteban et al. (2010), Rodríguez et al. (2013) y Guzmán y Rodríguez (2016). Los desastres por los fenómenos hidrometeorológicos causan severos daños y, a la vez, para repararlos, demandan fuertes inversiones. Lo anterior implica un retroceso o un estancamiento social; las autoridades y la sociedad en general deben estar preparadas para enfrentar tal situación. Los desastres tienden a ser "más y peores" por la confluencia de los impactos de la acción de las élites mundiales sobre el medio ambiente (Mitlin y Satterthwaite, citados en Rodríguez, 1996); hay un encadenamiento de desastres de origen natural con desastres tecnológicos y con el crecimiento urbano que genera patrones espaciales complejos de vulnerabilidad (Rodríguez, 1996). Un huracán, por las condiciones climatológicas, se produce de manera natural, sin embargo, su intensidad se asocia con las actividades humanas y otros factores.

Los participantes en este estudio consideran que se han presentado lluvias fuertes en otros tiempos y no han causado destrozos como ahora. Los destrozos o afectaciones se asocian con lo que comentó la población objeto en el sentido de que hubo algunos factores que influyeron para que estas zonas de la comunidad fueran afectadas. Así pues, se comprende que las afectaciones no fueron solamente a raíz del exceso de lluvias, sino también por actividades antropogénicas que ha llevado a cabo la población, falta de desazolve de arroyos o canales, incluso por la disposición inadecuada de los residuos sólidos, entre 


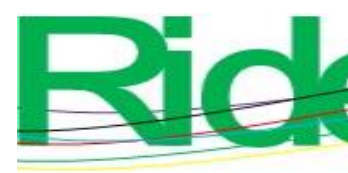

Revista Iberoamericana para la Investigación y el Desarrollo Educativo ISSN $2007-7467$

otras. También se incluye en la ecuación la contaminación que a diario se realiza, por la que se ha modificado el clima.

Las afectaciones que se presentaron en la comunidad se dieron por el desbordamiento del arroyo, del charco y de los canales de riego, también porque se modificaron niveles de terreno en las zonas donde están ubicados, en consecuencia, una sección del canal de riego fue entubada, esto en las orillas de la colonia Santa Cruz y la Tabiquería. La presencia de residuos sólidos en la zona afectada, en el charco y afluentes de agua, la cancelación de canales que servían como dren de aguas, las lluvias intensas y vientos contribuyeron a que se diera esta situación. Con esto se comprende que hubo otros factores implicados. Al parecer, las causas son similares a los estudios referentes de este estudio. Las dependencias gubernamentales finalmente apoyaron con despensas y otros materiales, como los de limpieza, por ejemplo; no se apoyó a la población en la reparación de daños, no obstante, algunos dicen que sí se recibieron algunos apoyos.

En cuanto a la percepción del riesgo, las personas ni las autoridades están organizadas para enfrentar situaciones como estas, no se contaba con un plan para investigar y corregir algunas causas que originaron el problema. Sin duda, la participación ciudadana, de grupos de la sociedad civil, apoyó desde el momento de la contingencia, para sacar a la gente de sus casas cuando estaban siendo inundadas, y posteriormente algunas personas e instituciones apoyaron con ropa, con despensas, medicinas, entre otras acciones. También se observó el apoyo de instituciones como la parroquia de la misma comunidad y escuelas, principalmente de la Universidad Autónoma de Guerrero.

Con respecto a la falta de coordinación entre Gobierno y sociedad para actuar en casos como estos, surge la necesidad de plantear estrategias de prevención y actuación ante contingencias como estas. De acuerdo con Rodríguez (1996), se considera necesario discutir las modalidades, alcances, limitaciones y perspectivas de la participación ciudadana en la prevención de desastres, estrechamente relacionada con la necesaria autonomía de la sociedad civil respecto a los poderes públicos, así como con la aún distante descentralización de las decisiones fundamentales (que tienen que ver con la vida misma) hacia la sociedad y a los niveles locales de Gobierno, sobre todo en los países subdesarrollados.

Diversos trabajos han constatado que las calamidades de origen natural o humano tienden a afectar a los grupos social, económica y culturalmente más pobres y vulnerables. Varios países frecuentemente expuestos a eventos disruptivos (como Japón, Australia, Estados Unidos y Colombia) han desarrollado estrategias preventivas apoyadas en la 


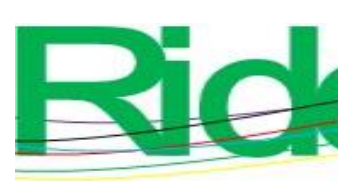

Revista Iberoamericana para la
Investigación y el Desarrollo Educativo
ISSN $2007-7467$

educación formal e informal, la capacitación y la amplia difusión de información (con ayuda de las escuelas, las organizaciones sociales, las empresas y los medios de comunicación), gracias a lo cual se han logrado disminuir significativamente las pérdidas materiales y humanas ocasionadas por desastres naturales y tecnológicos (Dettmer, 2002). Esta aseveración posiciona a la educación como una herramienta fundamental para que las personas no solo adquieran estrategias de prevención, sino para minimizar los riesgos y problemáticas (desastres) ocasionadas por fenómenos naturales.

\section{Conclusiones}

Los desastres naturales sitúan a las personas a vivir momentos de zozobra y a despertar inquietudes sobre lo acontecido. Las tensiones se convierten en necesidades en donde los afectados solicitan cubrirlas. En ese momento es de suma importancia la solidaridad social en donde particulares, instituciones o grupos de la sociedad civil apoyen las situaciones adversas que sufrieron estas personas.

Este estudio cumplió su propósito y dio respuesta a las interrogantes planteadas sobre el impacto causado por las afectaciones que sufrieron algunas personas al paso del huracán Max en la comunidad estudiada.

En relación a lo antes expuesto se identificó en la bibliografía revisada que existe relación entre las actividades antropogénicas, la contaminación ambiental y la alteración del clima y, por ende, los huracanes. Aunque el huracán es un fenómeno natural, en algunos casos sus efectos se complican por la vulnerabilidad social y de la zona donde representan, además porque la gente que ahí habita desconoce las medidas o el actuar ante los riesgos que implica, así mismo, y también por la cultura ambiental que poseen es insuficiente.

En las Vigas, el huracán Max tuvo impactos ambientales, lluvias y fuertes vientos, por lo cual se presentaron caída de árboles y desbordes de cuerpos de agua, lo que causó corrientes inmensas e inundaciones y esto, a su vez, llevó a hacer destrozos en infraestructuras de caminos, viviendas, pérdidas de bienes materiales, entre otros. Paralelamente, otros problemas internos y de tipo social se presentaron, como se describe en los resultados y discusión del análisis presentado.

En Las Vigas muchas personas afectan el medio ambiente inconscientemente con sus prácticas dañinas, con el inadecuado manejo y disposición de los residuos que producen y que pueden llegar a contaminar los suelos y el aire, por ejemplo. En algunos casos, 


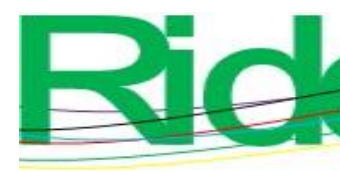

Revista Iberoamericana para la Investigación y el Desarrollo Educativo ISSN $2007-7467$

campesinos del lugar usan irracionalmente los pesticidas y agroquímicos para eliminar plagas, o también como método de fumigación para eliminar la hierba en sus huertos e inclusive en sus casas. Ejemplos como estos hacen posible comprender la afectación que se hace al medio ambiente. Se encontró también que habitantes extraen arena del arroyo, dejan residuos dentro del charco y arroyo del poblado, modifican estructuras de terrenos sin realizar estudios de impactos ambientales, esto conlleva a hacer vulnerable la zona y, por consiguiente, se refleja la inadecuada percepción de riesgo en los habitantes.

Así pues, las vulnerabilidades de inundaciones en la zona son por dos razones, las naturales y por las afectaciones y modificaciones que realizan las personas. Algunos ciudadanos comentaron que anteriormente sí se inundaba, pero no en gran magnitud. Con Max se rebasaron los límites, entonces, lo natural son las lluvias fuertes y la otra parte fueron las afectaciones que hacen las personas al entorno y a la modificación de las zonas.

Sin duda es importante que las personas del lugar promuevan conocimientos, habilidades y valores a través de la educación ambiental para la sustentabilidad para desarrollar estrategias de prevención y mitigación ante riesgos ambientales que afectan la integridad de la comunidad en general.

Debido al calentamiento global, en estos tiempos y los que vienen los huracanes serán de grandes magnitudes y, por este hecho, más devastadores; en correspondencia, las personas que habitan en comunidades con características como las que se describen en este estudio deben estar preparadas, si bien existen algunos factores que impiden que ello se logre, entre ellos evidentemente la vulnerabilidad social, la pobreza, la falta de educación, pensamiento ambiental y cultura de percepción del riesgo. Lo anteriormente dicho se relaciona con Dettmer (2002) cuando afirma que efectivamente existen factores que impiden que las personas enfrenten responsablemente las afectaciones producidas por dichos fenómenos, sin embargo, no deja de mencionar a la educación y papel tan muy importante que juega. La educación debe incorporar la importancia del medio ambiente con un enfoque sustentable, es decir, hacer comprender en las personas que la preservación y conservación del entorno es sumamente importante para alcanzar la sustentabilidad social que se requiere. 


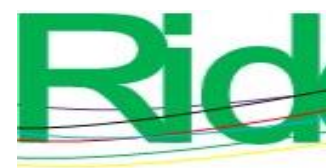

Revista Iberoamericana para la
Investigación y el Desarrollo Educativo
ISSN $2007-7467$

Futuras líneas de investigación

Este estudio es referente para futuras investigaciones que tengan lugar dentro del campo de las ciencias ambientales, la educación ambiental para la sustentabilidad y estudios sobre la percepción de riesgos ambientales. Al igual que en investigaciones similares desarrolladas en otras partes de México y en algunos países, esta marca la pauta para comprender cuáles fueron las causas y afectaciones originadas por inundaciones y otras más al paso del huracán Max. Es un referente directo para estudios que se realicen en esta comunidad o zona y principalmente en el estado de Guerrero. Cuando suelen suceder fenómenos de esta índole, se aprecian inundaciones y afectaciones ambientales en varias partes, aunado a las afectaciones económicas y sociales. Se sugiere orientar líneas de investigación en la identificación de causas que originan los desastres e inundaciones provocadas. Existe la incertidumbre de conocer el origen de las causas cuando se presenta una inundación. La gente comúnmente comenta que es por el paso del huracán o por las lluvias intensas, sin embargo, las prácticas desmedidas por afectar al medio ambiente y las modificaciones que se hacen a los terrenos también influyen en ello. El resultado y análisis comprendido marcó la pauta para sugerir que la población fomente la cultura de la prevención de riesgo y la ambiental a través de la educación ambiental para la sustentabilidad para así coadyuvar en promover conocimientos, habilidades y valores en el cuidado y preservación del entorno en habitantes de la comunidad objeto de estudio. 


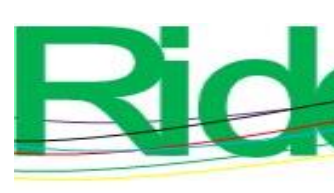

Revista Iberoamericana para la Investigación y el Desarrollo Educativo ISSN $2007-7467$

\section{Referencias}

Alcántara, M. y Bourrut, H. (2006). Educación ambiental, biodiversidad, espacios naturales y naturaleza. En La educación ambiental en Aragón en los albores del siglo XXI (4547). España: Gobierno de Aragón, Departamento de Desarrollo Rural y Sostenibilidad.

Alfaro, E. J., Quesada, A. y Solano, F. (2011). Análisis del impacto en Costa Rica de los ciclones tropicales ocurridos en el Mar Caribe desde 1968 al 2007. Diálogos. Revista Electrónica de Historia, 11(2), 27-34.

Angelotti, P., G. (2014). Acciones gubernamentales frente a los desastres provocados por fenómenos hidrometeorológicos en México. 17, (2), 70.

Angulo, L. E. (2011). Política fiscal y estratégica como factor de desarrollo de la empresa comercial de mediano tamaño sinaloense, un estudio de caso. (Tesis doctoral). Universidad Autónoma de Sinaloa.

Caballero, M., Lozano, S. y Ortega, B. (2007). Efecto invernadero, calentamiento y cambio climático: una perspectiva desde las ciencias de la Tierra. Revista Digital Universitaria 8(10), 2-12.

Cárdenas, M. J. (coomp. ${ }^{a}$ ) (2010). México ante el cambio climático. Evidencias, impactos, vulnerabilidad y adaptación. Ciudad de México, México: Greenpeace México.

Comisión Nacional del Agua [Conagua]. (2017). Max se intensificó a huracán categoría 1, frente a las costas de Guerrero. Comunicado de prensa núm. 561-17.

Comisión Nacional del Agua [Conagua]. (2017). Servicio Meteorológico Nacional. Huracán "Max" del océano Pacifico del 13 al 15 de septiembre de 2017. México: Comisión Nacional del Agua.

Definición ABC. (2010). Definición de Tormenta Tropical. Recuperado de https://www.definicionabc.com/medio-ambiente/tormenta-tropical.php.

Dettmer, G. J. (2002). Educación y desastres: reflexiones sobre el caso de México. Revista Latinoamericana de Estudios Educativos, 32(2), 43-72.

Díaz, G. (2012). El cambio climático. Ciencia y Sociedad, 37(2), 228-229.

Echemendía, T. B. (2011). Definiciones acerca del riesgo y sus implicaciones. Revista Cubana de Higiene y Epidemiología, 49(3), 470-481.

Ferrari, M. P. (2012). Análisis de vulnerabilidad y percepción social de las inundaciones en la ciudad de Trelew, Argentina. Revista Colombiana de Geografía, 21(2), 99-116. 

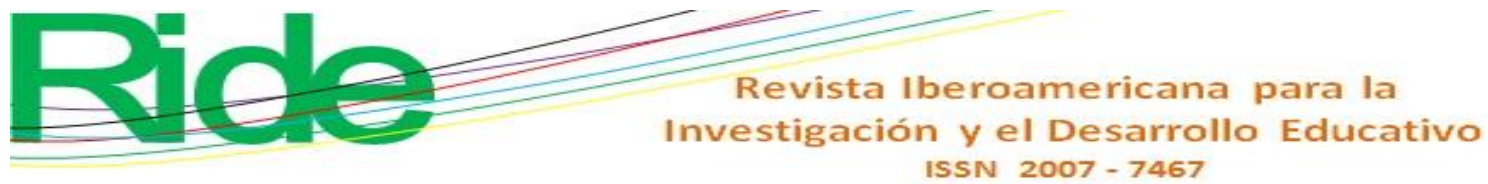

Fula, K., y Ayala, C. (2007). Calentamiento global. Más que un tema de moda. Impacto Ambiental. Recuperado de https://es.slideshare.net/jorgevilladiego-02/calentamientoglobal-13819988.

Galindo, J. (2015). El concepto de riesgo en las teorías de Ulrich Beck y Niklas Luhmann. Acta Sociológica, (67), 141-164.

Guzmán, G., y Rodríguez, J. M. (2016). Elementos de la vulnerabilidad ante huracanes. Impacto del huracán Isidoro en Chabihau, Yobaín, Yucatán. Política y Cultura, (45), 183-210.

Hernández, A. (2007). Reseña del huracán "Henriette” del océano Pacífico. México: Conagua/Semarnat.

Hopwood, B., Mellor, M. y O’Brien, G. (2005). Sustainable Development: Mapping Different Approaches. Sustainable Development, 13, 38-52.

Mendieta, I. G. (2015). Informants and sampling in qualitative research. Andean Research, 17(30).

Murray, G. y Murray, G. (2012). Clima desbocado. ¿Cómo Ves?, (168), 11.

Novo, M. (2005). Educación ambiental y educación no formal: dos realidades que se realimentan. Revista de Educación, (338), 145-165.

Olaguez, J. E. y Espino, P. (2013). Perspectivas de educación ambiental en las instituciones de educación superior. Revista Iberoamericana de las Ciencias Biológicas Agropecuarias, 2(3).

Ordóñez, M. M., Montes, L. M. y Garzón, G. del P. (2018). Importancia de la educación ambiental en la gestión del riesgo socio-natural en cinco países de América Latina y el Caribe. Revista Electrónica Educare, 22(1), 1-19.

Organización de las Naciones Unidas para la Educación y Diversificación, la Ciencia y la Cultura [Unesco]. (2005). Educación para el Desarrollo Sostenible (EDS).

Quiroz, B. I., del Amo, R., Ramos, P. J.M. (2011). Desarrollo sustentable, ¿Discurso político o necesidad urgente? Revista de Divulgación Científica de la Universidad Veracruzana, (XXIV) (3).

PueblosdeAmerica.com. (s. f.). Las Vigas (San Marcos, Guerrero). Recuperado de https://mexico.pueblosamerica.com/i/las-vigas-4/.

Rodríguez, B. M. (2007). Ingeniería y medio ambiente. Revista de Ingeniería, (26), 56-63.

Rodriguez, V. D. (1996). El futuro de la participación ciudadana ante desastres. Desastres y sociedad, 6, 1-26. 


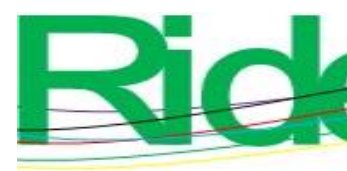

Revista Iberoamericana para la Investigación y el Desarrollo Educativo ISSN $2007-7467$

Rodríguez, S. A., Berro, T. B., Valdez, V. O. y Quintana, J. I. (2012). Principales riesgos de desastres en Cuba. En López, C. (ed. $\left.{ }^{a}\right)$, Educación ambiental. Prevención, gestión y manejo del riesgo en situaciones de desastres (pp. 1-119). Habana, Cuba: Ciencias Médicas.

Rodríguez, S., Gelis, M. y Fornaris, E. (2013). Análisis del impacto ambiental del huracán Sandy en la comunidad Los Cangrejitos. Ciencia en su PC, (1), 11-20.

Santiago, A. (2009). La globalización del deterioro ambiental. Aldea Mundo, 14(27), 63-72. Santiesteban, Y., Castro, M., González, Z. y Sánchez, L. (2010). Impacto del paso de los huracanes Gustav e Ike en la salud psicológica de un grupo de escolares afectados. Revista Cubana de Medicina General Integral, 26(3), 508-515.

Secretaría de Medio Ambiente y Recursos Naturales [Semarnat]. (2009). Cambio climático. Ciencia, evidencia y acciones. Ciudad de México, México: Secretaría de Medio Ambiente y Recursos Naturales. Recuperado de http://www.conafor.gob.mx/biblioteca/cambio_climatico_09-web.pdf.

Sganderla, J., Rodrigo, E., y Rosado, F. (2010). La gestión pública y los riesgos medioambientales provenientes de la industrialización en el vale do Rio dos Sinos Brasil. Revista Bibliográfica de Geografía y Ciencias Sociales, 15(901). Recuperado de http://www.ub.edu/geocrit/b3w-901.htm.

Tréllez, E. (2002). La educación ambiental comunitaria y la prospectiva. Una alianza de futuro. Tópicos en Educación Ambiental, 4(10), 7-21.

Tréllez, E. (2004). Manual para Educadores. Educación Ambiental y Conservación de la Biodiversidad en los Procesos Educativos. Módulo II Elementos de investigación participativa y planificación prospectiva en la Educación Ambiental. 1 ed. CED Área de Medio Ambiente. Santiago-Chile.

Secretaría de Desarrollo Social [Sedesol]. (2013). Catálogo de localidades. Las Vigas 82052010. México: Secretaría de Desarrollo Social.

Toscana, A. A. (2003). Impacto del huracán Paulina en la política local de Acapulco. Política y Cultura, (19), 63-79.

Vargas, L. M. (1994). Sobre el concepto de percepción. Alteridades, 4(8), 47-53.

Vargas, I. (2012). La entrevista en la investigación cualitativa: nuevas tendencias y retos. Calidad en la Educación Superior, 3(1), 119-139. 


\begin{tabular}{|c|c|}
\hline Rol de contribución & Autor(es) \\
\hline Conceptualización & $\begin{array}{l}\text { Ramón Bedolla Solano, Adriana Miranda Esteban, Juan Jose } \\
\text { Bedolla Solano, Oscar Sánchez Adame }\end{array}$ \\
\hline Metodología & $\begin{array}{l}\text { Ramón Bedolla Solano, Adriana Miranda Esteban, Juan Jose } \\
\text { Bedolla Solano }\end{array}$ \\
\hline Software & Juan Jose Bedolla Solano \\
\hline Validación & Ramón Bedolla Solano, Adriana Miranda Esteban \\
\hline Análisis Formal & $\begin{array}{l}\text { Ramón Bedolla Solano, Adriana Miranda Esteban, Juan Jose } \\
\text { Bedolla Solano, Oscar Sánchez Adame }\end{array}$ \\
\hline Investigación & $\begin{array}{l}\text { Ramón Bedolla Solano, Adriana Miranda Esteban, Juan Jose } \\
\text { Bedolla Solano, Oscar Sánchez Adame }\end{array}$ \\
\hline Recursos & $\begin{array}{l}\text { Ramón Bedolla Solano, Adriana Miranda Esteban, Juan Jose } \\
\text { Bedolla Solano, Oscar Sánchez Adame }\end{array}$ \\
\hline Curación de datos & Ramón Bedolla, Adriana Miranda Esteban \\
\hline $\begin{array}{l}\text { Escritura y preparación del } \\
\text { borrador original }\end{array}$ & Ramón Bedolla, Adriana Miranda Esteban \\
\hline Escritura y revisión y edición & Ramón Bedolla, Adriana Miranda Esteban \\
\hline Visualización & Oscar Sánchez Adame, Adriana Miranda Esteban \\
\hline Supervisión & Ramón Bedolla Solano, Adriana Miranda Esteban \\
\hline Administración de proyectos & Ramón Bedolla Solano \\
\hline Adquisición de fondos & Ramón Bedolla Solano \\
\hline
\end{tabular}

